\title{
Development of a Web Based Expert System for Rubber Crop Disease Diagnosis and Management
}

\author{
S. Konyeha*, F. A. Imouokhome \\ Department of Computer Science, University of Benin, Nigeria
}

Received 3 December 2017, accepted in final revised form 3 June 2018

\begin{abstract}
An expert system imitates the decision-making adeptness of a human expert. They are intended to answer complicated questions characterized mainly as if-then rules instead of traditional procedural code. A major problem facing the cultivation of rubber (Hevea brasiliensis) in developing countries is the destructive effect of pathogens which result in about fifty percent $(50 \%)$ loss in crop yield. This problem persists, due to a communication gap between agricultural researchers, such that field extension officers, and farmers are hampered by various operational and logistic challenges. This paper is an effort to bridge this gap, and hence features an expert system that can be accessed online by farmers. The expert system allows farmers to select disease symptoms presented in categories from a JAVA based user friendly graphical interface. The output generated by the rule-base engine, diagnoses the diseases of the rubber crop, and suggests curative and preventive measures. The main source of information for developing the expert system' knowledgebase was the Rubber Research Institute, Iyanomo, Edo State, Nigeria.
\end{abstract}

Keywords: Expert system; Rubber; Hevea brasiliensis; GMDH technique; CLIPS Shell.

(c) 2018 JSR Publications. ISSN: 2070-0237 (Print); 2070-0245 (Online). All rights reserved. doi: http://dx.doi.org/10.3329/jsr.v10i3.34786 J. Sci. Res. 10 (3), 239-248 (2018)

\section{Introduction}

Rubber (Hevea brasiliensis) is a major cash crop in Nigeria as the country's climate is well suited for the cultivation of the crop which has great potential of being a significant source of foreign exchange. Recent reports suggest that there has been a decline in rubber production in Nigeria [1]. This is worrisome and alarming to the country's economy, as rubber production and export can revitalize the economy through revenue, employment and rural development. Several challenges bedevil this promising industry. Most notable of these problems is the effect of diseases like White rot, Bird's eye spot, Shoot rot etc., on crop yield [2]. Yield losses of over 50\% have being reported. Such a situation is untenable, and with most of rubber production in the hands of small holders which cover an estimated area of 195,000 hectares out of a total arable land devoted to rubber growing

\footnotetext{
*Corresponding author: susan.konyeha@uniben.edu
} 
of 260000 ha in the country (others: large plantations, private owned and state owned) [3], the problem may be traced to improper management of these plant diseases. An investigative study by the researcher revealed that most of these local farmers and others who engage in anarchical gathering in the Hevea forest have inadequate access to expert knowledge in diagnosing and managing rubber crop diseases.

The aim of this study is to develop a web-based application for rubber crop disease diagnosis and management using an expert system. The approach is chosen as it is capable of handling uncertainty derived from inaccurate or imprecise data entered by the farmers or in the knowledge base of the expert system.

\subsection{Overview on expert system}

An expert system is a computer program simulating the pattern of problem solving by a human expert [4]. It applies knowledge and inference procedures in solving problems that require human intelligence and expertise [5]. It pluralizes the benefit attributable from a single expert, by storing information and knowledge from an expert domain using rules, which through an inference engine deductions are made and presented at a user interface by which several users entering queries will derive results. It also enables the transference of knowledge that would otherwise be given by an expert in the absence of an expert. This design protocol has its advantages as it could be cheaper, and multiplies access to knowledge. An expert system consists principally of three parts: a user interface, a knowledge base where information and data is stored, and an inference engine which is the reasoning mechanism that deduces hypothesis from the knowledge base using logical rules [6]. Expert systems are increasingly deployed in diagnostic science, notably in medicine for the diagnosis of diseases like Diabetes Mellitus, Hepatitis [6], Leukemia [7] thyroid disorders [8] and many others. They are also applied to a large extent for the detection of plant disease. Barbedo [9] conducted a survey and critical review of expert systems applied to plant disease diagnosis, for example an expert system has been deployed in the detection of coffee rust [10], cereal leaf diseases [11], tobacco disease [12], and other plant diseases. This paper presents the development of a rubber crop disease diagnosis expert system for local farmers in Nigeria, to which human expert knowledge on disease detection and treatment could be inaccessible, expensive or sometimes inadequate. The novelty of this expert system which motivated the study is that it seeks to bridge the gap usually found in this area of research where the real needs of the field users are not considered [9]. The proposed expert system works by incorporating software tools into an expert system capable of translating technical advances into an agricultural aid that can be accepted by the potential users(farmers), a technological resource which is lacking, especially in underdeveloped countries like Nigeria.

\section{Methodology}

We used the Group Method of Data Handling (GMDH) technique for modeling the rubber crop disease diagnosis and management expert system. GMDH is a family of inductive 
algorithms for computer-based mathematical modeling of multi-parametric datasets that features fully automatic structural and parametric optimization of models. A GMDH model with multiple inputs and one output is a subset of components of the base function.

$Y\left(x_{1}, x_{2}, \ldots, x_{n}\right)=a_{0}+\sum_{i=1}^{m} a_{i} f_{i}$

where $f$ are elementary functions dependent on different sets of inputs, $a$ are coefficients and $m$ is the number of the base function components. Some of the studied rubber crop disease and symptoms are shown in Table 1.

Table 1. Some of the studied rubber crop disease and symptoms.

\begin{tabular}{|c|c|c|c|}
\hline $\begin{array}{ll}\text { Part } & 0 \\
\text { plant } & \\
\text { affected }\end{array}$ & Disease & $\begin{array}{l}\text { Potential for } \\
\text { damage }\end{array}$ & Symptoms \\
\hline $\begin{array}{l}\text { Nursery } \\
\text { seedlings }\end{array}$ & Bird's Eye Spot & High & $\begin{array}{l}\text { Symptoms appear as small necrotic spots with } \\
\text { dark/brown margins and pale Centre. Severe } \\
\text { infection leads to premature defoliation and die back. }\end{array}$ \\
\hline $\begin{array}{l}\text { Tender } \\
\text { green } \\
\text { shoots rot }\end{array}$ & Shoot Rot & High & $\begin{array}{l}\text { The tender green shoots rot. More damaging for } \\
\text { nursery seedlings and the young plants in the field. }\end{array}$ \\
\hline $\begin{array}{l}\text { Infects } \\
\text { tender } \\
\text { leaves }\end{array}$ & $\begin{array}{l}\text { Colletot-richum } \\
\text { Leaf Disease }\end{array}$ & High & $\begin{array}{l}\text { Infects tender leaves, mostly at the leaf tip region. } \\
\text { Spots are small, brown in colour, and are surrounded } \\
\text { by a yellow hallo. Numerous spots coalesce and dry } \\
\text { up leading to defoliation. The infected leaves often } \\
\text { crinkle and become distorted before shedding. }\end{array}$ \\
\hline $\begin{array}{l}\text { Nursery } \\
\text { seedlings }\end{array}$ & Leaf Spot & $\begin{array}{l}\text { Low to } \\
\text { moderate }\end{array}$ & $\begin{array}{l}\text { Appearance of large spots, with brown margins and } \\
\text { pale centre, is the common symptom. The centre may } \\
\text { fall off forming shot holes. On mature trees light } \\
\text { green leaves during re-foliation are more } \\
\text { susceptible. Several lesions coalesce to form large } \\
\text { blighted area. Disease spreads along the veins } \\
\text { leading to a brownish "railway track" or fish bone" } \\
\text { like appearance. Even a localised infection on midrib } \\
\text { or base of a leaf causes leaf abscission. Defoliation } \\
\text { leads to die-back of branches }\end{array}$ \\
\hline $\begin{array}{l}\text { Infects } \\
\text { leaves }\end{array}$ & $\begin{array}{l}\text { Blossom-End } \\
\text { Rot }\end{array}$ & High & $\begin{array}{l}\text { Moisture by consistent watering (around 1-inch per } \\
\text { week is a good starting point). Keep soil pH around } \\
6.5 \text {, Add calcium to soil by spreading crushed } \\
\text { eggshells around the plant, by applying bone meal, or } \\
\text { use agricultural or dolomitic lime, which is readily } \\
\text { available where lawn fertilizers are sold, to preserve } \\
\text { soil moisture spread a protective layer of a material } \\
\text { on top of the soil. Organic mulches such as leaves, } \\
\text { grass clippings, straw, bark, and similar materials are } \\
\text { excellent and improve the soil, Avoid damaging root } \\
\text { systems by not cultivating too close to the plant }\end{array}$ \\
\hline
\end{tabular}


In order to find the best solution GMDH algorithms consider various component subsets of the base function (1) called partial models. Coefficients of these models are estimated iteratively. The most popular base function used in GMDH is the gradually complicated Kolmogorov-Gabor polynomial,

$Y\left(x_{1}, x_{2}, \ldots, x_{n}\right)=a_{0}+\sum_{i=1}^{n} a_{i} x_{i}+\sum_{i=1}^{n} \sum_{j=1}^{n} a_{i j x_{i} x_{j}}+\sum_{i=1}^{n} \sum_{j=1}^{n} \sum_{j=1}^{n} a_{i j k} x_{i} x_{j} x_{k}+$

The resulting models are also known as polynomial neural networks. GDMH is one of the earliest deep learning methods for training neural nets [13]. Table 2 shows some selected symptoms of Rubber diseases.

Table 2. Some Selected Symptoms of Rubber Diseases.

\begin{tabular}{ll}
\hline Symptom & Response \\
\hline Does the leaf have round lesions or spots? & Yes/ No \\
Does it have gray or white dead center? & Yes/ No \\
Does it have decayed germinated seed? & Yes/ No \\
Does it have no emergence of seedlings? & Yes/ No \\
Does it have white moldy growth? & Yes/ No \\
Does it have lessions parallel to leaf veins & Yes/No \\
Does it have brown discoloration of growing plant, leaf base & Yes/No \\
Does it have decayed germinated seed & Yes/No \\
Does it have gray or white dead center & Yes/No \\
\hline
\end{tabular}

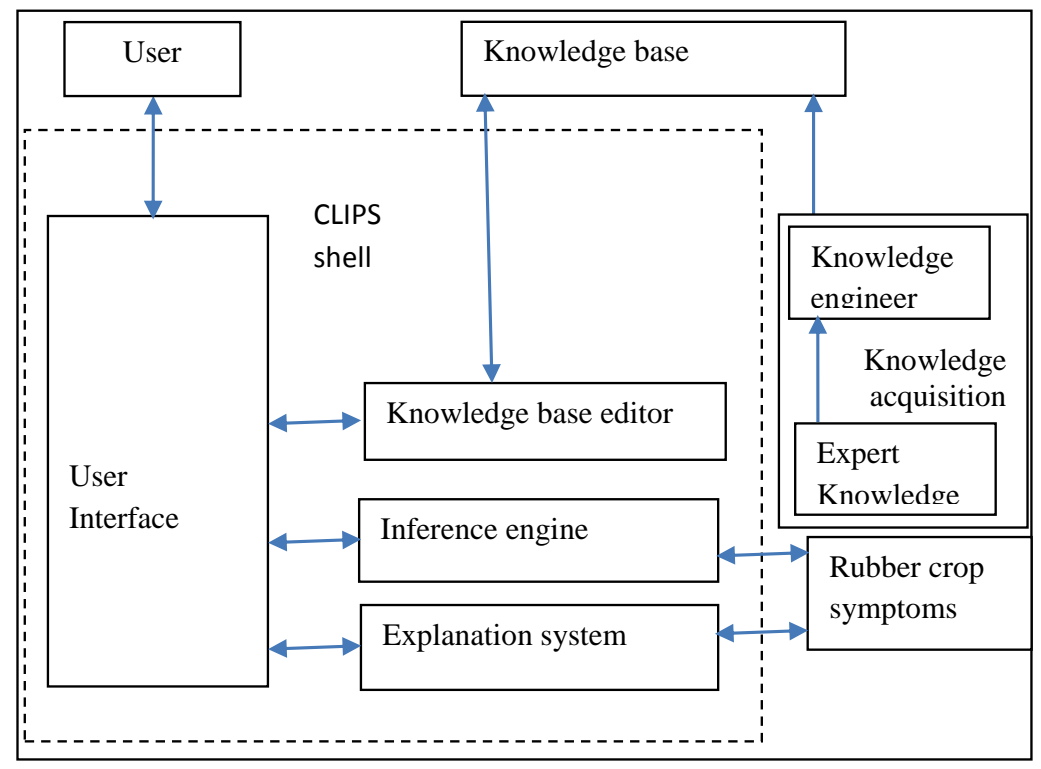

Fig. 1. Architecture of the expert system. 
The architecture of the system is shown in Fig. 1, and the major components which include the knowledge base acquisition, the knowledge representation, inference engine and expert system shell are described.

\subsection{Knowledgebase acquisition}

It is considered vital that if an expert system is to give an intelligent advice about a particular domain, it must have access to as much domain knowledge as possible. The knowledge base is one of the basic tools for expert system construction and stores information pertaining to the domain under consideration for future recall. In this study, rubber crop disease pathology is the expert domain. Basic information about the rubber diseases, risk factors, symptoms and treatment were collected from the Rubber Research Institute of Nigeria (RRIN) Iyanomo, Benin City, Edo State Nigeria. Additional information was also collected from books, websites and journals.

\subsection{Knowledge representation}

The collected information was converted into Java syntax and entered into the knowledge base (that is facts and rules). The inference engine was populated and consists of five (5) rules. The explanation system gives a brief description of the cause of each symptom. So the expert system can assist the user by giving information about the symptom or the cause of the rubber crop disease.

\subsection{Inference engine and expert system shell}

The function of expert system is to use the symptom set given as input, fit it to a disease by the help of the expert systems knowledge base and inference engine then suggest curative/preventive methods for the rubber crop. The system consists of three basic components, which are, the knowledge base", "inference engine" and a "user interface". The rubber crop diseases expert system is dependent on user input, i.e. is data-driven, hence it uses a forward chaining inference engine. The inference engine is used to determine how the rules in the knowledge base are applied to the problem i.e. the inference engine determines which in the knowledge base, executes the rules, and determines when an acceptable solution has been found.

It can be said that, without a friendly "user interface", the expert system is useless. The user interface is the third component of the expert system, through which a user is able to interact with the system and get answers to questions.

The expert shell used in this work is CLIPS (C Language Integrated Production System), an expert shell written in C. It is chosen for the fact that it has a forward chaining inference engine and is a free expert system shell distributed by NASA. It is a generalpurpose problem-solving "engine" for handling rules and facts. 


\section{Analysis of the System}

We specified nineteen rubber disease symptoms to create rules for the system. To manage these nineteen symptoms, eleven rules representing in the main menu, the rule for viewing symptoms, and prevention of rubber diseases were used. Depending on the disease type selected by the farmer or rubber expert, the causes, prevention and treatment will be displayed on the system. The system can give reasoning based on the category of symptom selected on the interface design. Samples of rules used in the design are presented below.

\subsection{Sample rules for the system}

If the selection is "RUBBER DISEASES SYMPTOMS DIAGNOSIS."

(THEN start to diagnose)

(Suggest Disease type)

(Display possible causes)

(Display possible prevention)

(Display possible treatment)

(if (eq? category 1)

THEN

Start to diagnose (Type of Rubber Disease)

Rule 1: If the selection category is equal to? ' $16,17,18,19$ '

(View Information about' Sunscald')

Else

(if selection is not equal to? ' $16,17,18,19$ ')

"Disease Not Found"

Then

Reselect category

Rule 2: If the selection category is equal to? '3,4,5,6'

(View Information about 'Anthracnose Disease')

Else

(if selection is not equal to? ' $3,4,5,6$ ')

"Disease Not Found"

Then

Reselect category

(View Information about 'Barkrot or black stripe')

Else

(if selection is not equal to? '30,31')

"Disease Not Found"

Else

Reselect category

(To Exit the program)

Then Go To Main Menu 


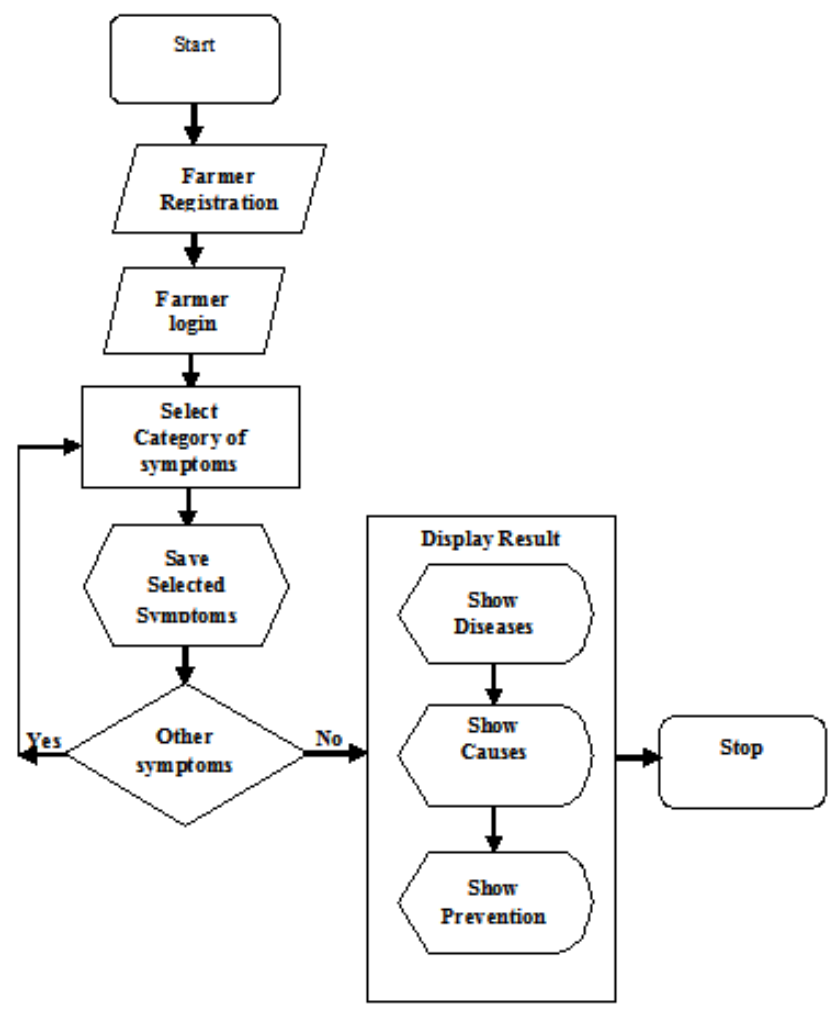

Fig. 2. Functional flow chart of the system.

The functional flowchart of the system is shown in Fig. 2. It entails the farmers registration, farmers login, categories of symptoms selected, the diseases, causes of the diseases and the prevention.

\section{System Implementation}

The system was implemented using several development tools specified in the design.

\subsection{Choice of development tools}

The development tools are the required tools to design the system. The listed packages were used because of their features, accessibility and reliability. They include: MariaDB (MySQL), phpMyAdmin, XAMPP, Apache, etc. 


\subsection{Modules interfaces}

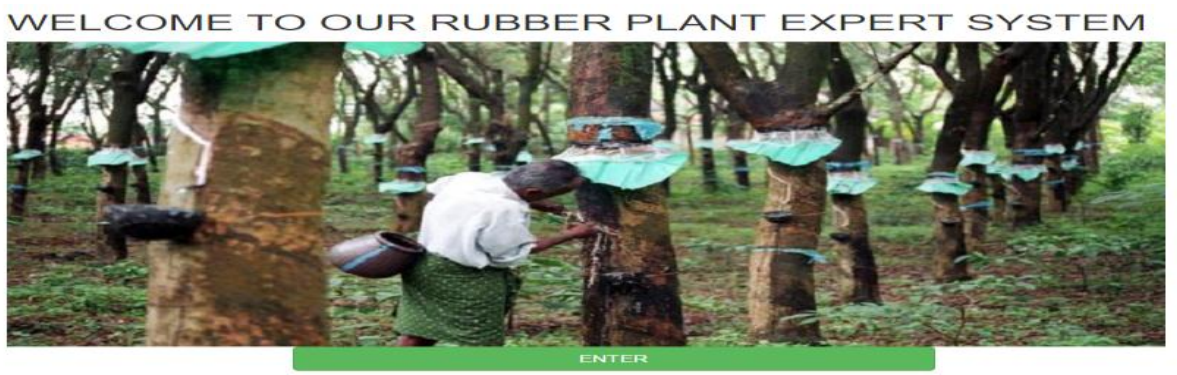

Fig. 3. Main interface

The Main interface that greets the user immediately the application is launched is shown in Fig. 3. The interface contains the enter button. The user is expected to click this button to start using the system.

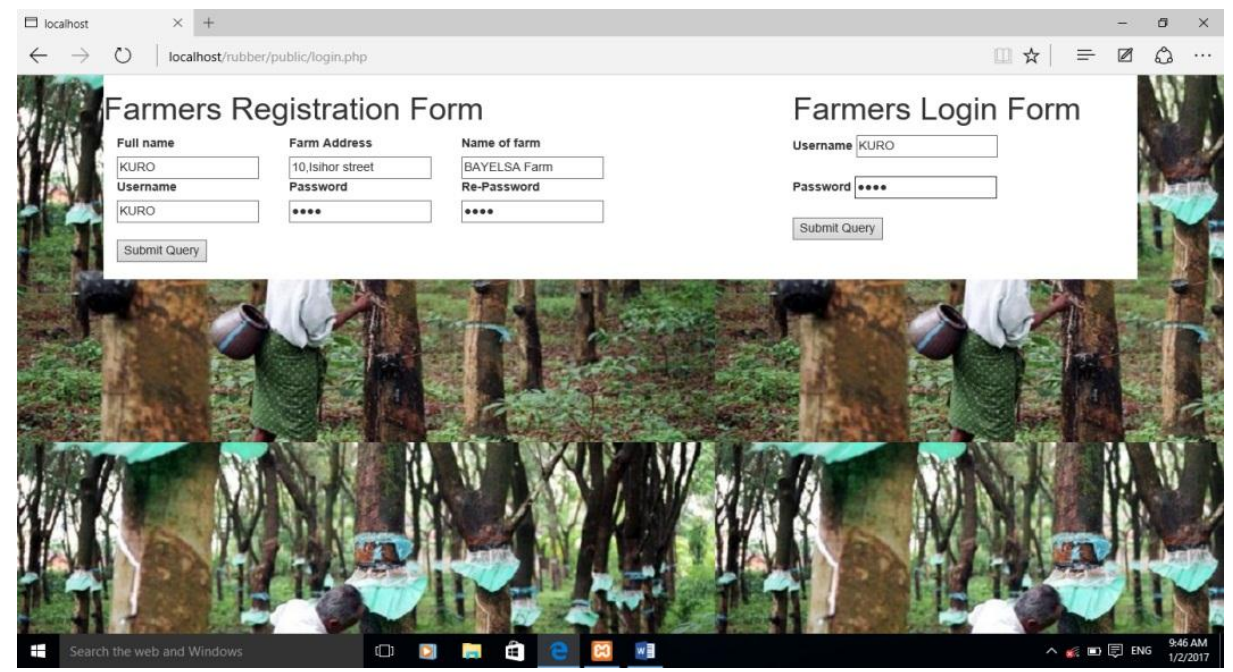

Fig. 4. Registration and login interface.

The Registration and login interface shown in Fig. 4 allows registration and login of farmer information into the system. 




Fig. 5. Interface for categorized symptoms.

The interface for categorized symptoms is shown in Fig. 5. This categorizes the different symptoms affecting the rubber crop.



Fig. 6. Sample result diagnosis interface for the selected symptom.

The sample result diagnosis interface for the selected symptom is shown in Fig. 6. This gives the preventions and causes of the rubber disease. 


\section{Conclusion}

The expert system developed was tested, with satisfactory results denoting the achievement of the set objectives by applying it to rubber disease diagnosis and management. The diagnosis was able to reveal the causes, prevention and the resultant disease of the rubber crop.

\section{Acknowledgment}

We are grateful to the Rubber Research Institute of Nigeria, Iyanomo, Pathology/ Disease Control Department staff members for their contribution to the successful actualization of this research.

\section{References}

1. V. Egunyanga, Rubber Production Declining. https://www.dailytrust.com.ng/daily/agriculture/2149, (Aug. 1, 2013)

2. N. O. Ogbebor, A. T. Adekunle, O. N. Eghafona, and A. I. Ogboghodo, Researcher 5, 181 (2013). https://doi.org/10.7537/marsrsj051213.24

3. Final Report, Proposals for the Development of the Rubber Research Institute of Nigeria (RRIN). Financed by the Commission of the European Communities (1991).

4. J. Durkin, Expert Systems: Design and Development, ${ }^{\text {st }}$ Edition (Prentice Hall, Englewood Cliffs, 1994).

5. P. M. N. Rani, R. Rajesh, and T. Sarvanan, J. Comput. Sci. Applicat. 3, 59 (2011).

6. M. A. D. A. Aziz, MS Thesis, King Saud University, Riyadh (2010).

7. J. C. Obi and A. A. Imianvan, Global J. Comput. Sci. Tech. 11, (2011).

8. A. A. Imianvan and J. C. Obi, Int. J. Fuzzy Logic Syst. (IJFLS) 2, (2012). https://doi.org/10.5121/ijfls.2012.2201

9. J. G. A. Barbedo, IEEE Latin Am. Transactions 14, 1910 (2016). https://doi.org/10.1109/TLA.2016.7483534

10. E. Lasso, T. T. Thamada, C. A. A. Meira, and J. C. Corrales, Graph Patterns as Representation of Rules Extracted from Decision Trees for Coffee Rust Detection, (Springer International Publishing, Cham, 2015) pp. 405. https://doi.org/10.1007/978-3-319-24129-6_35

11. R. kaur and S. Din, Int. J. Comput. Sci. Inform. Technol. 7, 1771 (2016).

12. H. Ravisankar, K. Sivaraju, D. D. Reddy, and N. S. Rao, J. Entomol. Zool. Stud. 6, 5 (2018).

13. J. Schmidhuber, Neural Networks 61, 85 (2015). https://doi.org/10.1016/j.neunet.2014.09.003 